\title{
A simple technique to measure TAPSE and MAPSE on CMR and normal values
}

\author{
Heerajnarain Bulluck ${ }^{1,2^{*}}$, Hataichanok Ngamkasem², Daniel Sado ${ }^{2}$, Thomas A Treibel ${ }^{2}$, Marianna Fontana ${ }^{2}$, \\ Viviana Maestrini ${ }^{2}$, James Moon ${ }^{2}$, Derek J Hausenloy ${ }^{1,2}$, Anna S Herrey ${ }^{2}$, Steven K White ${ }^{1,2}$ \\ From 17th Annual SCMR Scientific Sessions \\ New Orleans, LA, USA. 16-19 January 2014
}

\section{Background}

Mitral and Tricuspid Annular Plane Systolic Excursion (MAPSE, TAPSE) add valuable information to functional assessment of the right and left heart, highlighting abnormality even when ejection fraction is normal. To date, CMR-equivalents of MAPSE and TAPSE have been variably measured by a number of different methods but no formally published CMR guidelines on methodology, or normal values, exist. Further evaluation is required. The feasibility of a simple and quick technique is assessed in terms of its reproducibility, in order to provide age-stratified normal values.

\section{Methods}

Healthy volunteers $(\mathrm{n}=68,24$ to 83 years-old, 32 males) were recruited from local advertisements. CMRequivalent MAPSE and TAPSE were measured on standard 4-chamber SSFP cine images, independently by 2 blinded observers. The straight-line distance travelled by the lateral tricuspid and mitral annulus from end-diastole to end-systole was measured as shown in Figure 1. Inter-observer variability and intra-observer variability were calculated in a sample $(n=20)$ of subjects. Normal values were then grouped according to age: group 1: 2039 yrs $(\mathrm{n}=25)$; group $2: 40-59$ yrs $(\mathrm{n}=21)$ and group $3: \geq 60$ yrs $(\mathrm{n}=22)$.

\section{Results}

There was good inter-observer agreement for MAPSE (Intraclass Correlation Coefficient (ICC) of 0.84, 95\% CI $0.60-0.94, \mathrm{p}<0.001$ ) and TAPSE (ICC 0.77, 95\% CI $0.43-0.91, \mathrm{p}<0.05)$. There was also very good intraobserver agreement (ICC for MAPSE: 0.84, 95\% CI 0.64

${ }^{1}$ The Hatter Cardiovascular Institute, London, UK

Full list of author information is available at the end of the article
- 0.93, ICCC for TAPSE: 0.92, 95\% CI $0.80-0.97$, p < $0.001)$. There were no significant differences in MAPSE and TAPSE between genders. Subgroup analysis showed no difference in TAPSE in the 3 different age groups. MAPSE was different between groups 1 and 2 and but there was no statistical difference between groups 2 and 3 (Figure 2). Therefore, from our cohort of healthy individuals, TAPSE was $23.3 \pm 3.6 \mathrm{~mm}$ for the whole cohort. MAPSE was $14.8 \pm 2.4 \mathrm{~mm}$ for those between 20 to 39 years of age and $12.8 \pm 2.2 \mathrm{~mm}$ for those aged 40 years old and above.

\section{Conclusions}

MAPSE and TAPSE are easily measured, highly reproducible CMR parameters. Although these parameters should not replace formal volumetric evaluation of systolic function, they add value in patients with impaired left ventricular function despite normal EF (e.g. hypertrophic cardiomyopathy), complement our assessment of

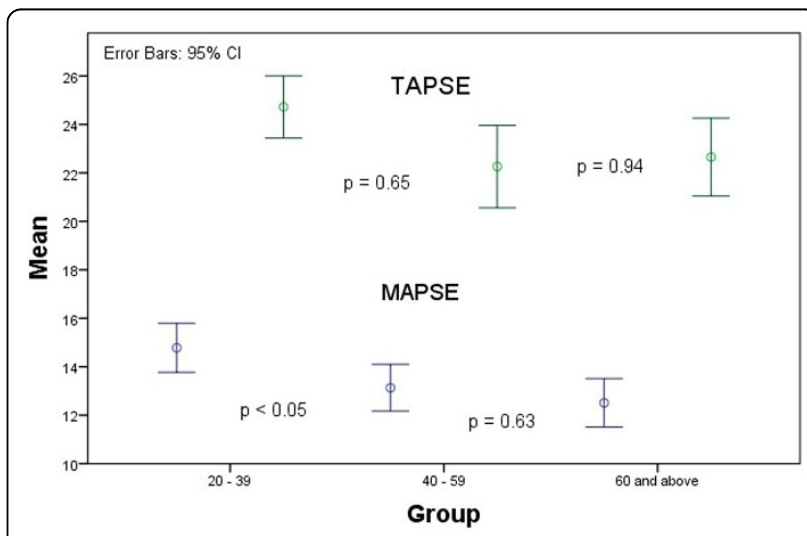

Figure 1 Error Bars with 95\% Confidence Interval for TAPSE (green) and MAPSE (blue) for the 3 age groups. 


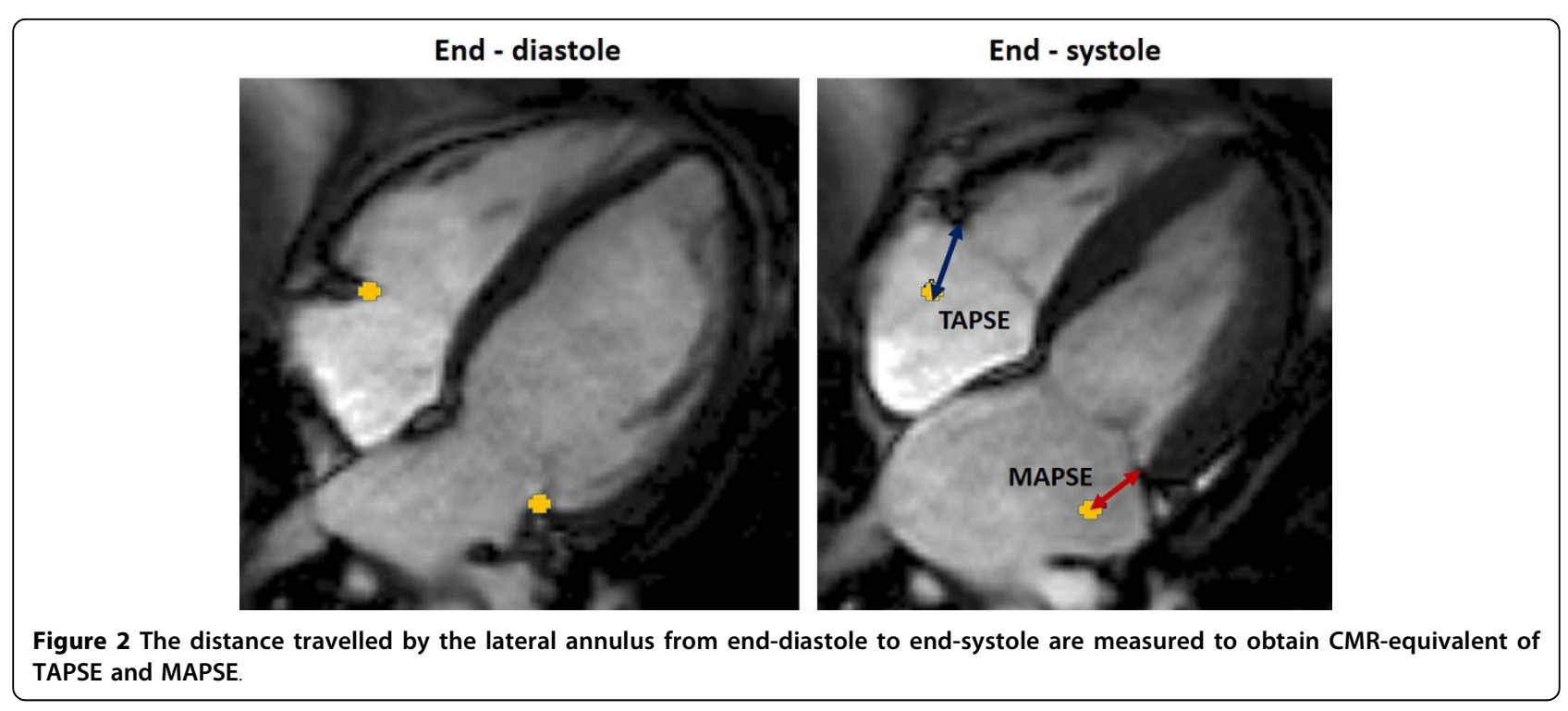

right ventricle function, and provide a platform to determine their clinical importance.

\section{Funding}

Dr Bulluck is employed by The Hatter Cardiovascular Institute. This work was undertaken at UCLH/UCL and a proportion of the funding came from the Department of Health National Institute for Health Research Biomedical Research Centres funding scheme.

\section{Authors' details}

${ }^{1}$ The Hatter Cardiovascular Institute, London, UK. ${ }^{2}$ Heart Hospital Imaging Center, Heart Hospital, University College London, London, UK.

Published: 16 January 2014

doi:10.1186/1532-429X-16-S1-P22

Cite this article as: Bulluck et al:: A simple technique to measure TAPSE

and MAPSE on CMR and normal values. Journal of Cardiovascular

Magnetic Resonance 2014 16(Suppl 1):P22.

Submit your next manuscript to BioMed Central and take full advantage of:

- Convenient online submission

- Thorough peer review

- No space constraints or color figure charges

- Immediate publication on acceptance

- Inclusion in PubMed, CAS, Scopus and Google Scholar

- Research which is freely available for redistribution 